\title{
Functional Apparel Needs of Lactating Mothers in Taraba State, Nigeria
}

\author{
Nzuta Vahey Janet, PhD \\ Department of Home and Rural Economics \\ College of Agriculture, P.M.B 1025, Jalingo, Taraba State, Nigeria
}

\section{ABSTRACT}

The major purpose of this study was to develop functional apparels for lactating mothers. In order to achieve this, ten specific purposes were stated to guide the study; eight research questions were posed while seven null hypotheses were formulated. The study adopted Research and Development ( $\mathrm{R}$ and $\mathrm{D})$ design and was carried out in Taraba State, Nigeria. The population for this study was 1475 respondents comprising of 1239 lactating mothers between the ages of 18-34, 162 Nurses, 34 Home Economics Extension Workers and 40 Registered Fashion Designers. Multi-stage and disproportionate stratified random sampling techniques were used to select 288 subjects for the study. Instruments for data collection in the study were Interview Schedule for Nurses on Need Assessment (ISNNA), Functional Apparel Needs Assessment Questionnaire for Lactating Mothers (FANAQLM), Interview Schedule for Home Economics Extension Workers and Fashion Designers on Need Assessment (ISHEFDNA). Focus Group Discussion (FGD) for Lactating Mothers on Need Assessment (FGDLMNA) and Questionnaire for Evaluation of Functional Lactating Apparels by Judges and user models (QEFAJUM). The instruments were subjected to face validation by five experts, two experts from the Department of Home Economics and Hospitality Management Education; one from Measurement and Evaluation, Department of Science Education; all of the University of Nigeria, Nsukka. One from College of Agriculture, Jalingo, and one from Federal University of Agriculture, Makurdi. In order to determine the reliability of the research instruments, the questionnaire (FANAQLM and QEFAJUM) were trial tested by administering thirty copies of the questionnaire to 30 respondents from Plateau State. The FANAQLM yielded reliability index of $0.85,0.78,0.93,0.81,0.66$ and 0.86 for clusters A, B, C, D, E and F respectively and an overall reliability index of 0.91 was determined for the instrument and QEFAJUM yielded a reliability index of 0.94 . This was done using Cronbach alpha reliability method. Based on the geographical spread of the population across the State, four research assistants from the Home Economic Section of College of Agriculture Jalingo who know the terrain of the study area were instructed on how data should be collected for the study while the researcher coordinated the activities of the four research assistants and collated the retrieved questionnaire after the period of administration for data analysis. All the instruments administered to the respondents were returned which represent $100 \%$ return rate. Mean and standard deviation were used for answering the research questions while ANOVA was used to test hypotheses 1-6 and t-test statistics was used in testing hypothesis 7, all at 0.05 level of probability. The findings of the study showed that lactating mothers engaged in 15 various operations/activities involved in lactation, there are 12 functional apparels' needs for lactating mothers, there are 19 design criteria to be
\end{abstract}

adopted to produce functional apparels to accommodate the needs/activities performed by lactating mothers, there are nine functional and five aesthetic design features preferred by the lactating mothers, there are four functional openings with fastening needs for easy and discreet lactation. Based on the findings of the study, seven functional apparels were developed and coded for easy identification. Therefore, the researcher recommends that clothing manufacturers, designers, and entrepreneurial should recognize functional apparel needs for lactating mothers during their process of construction. They should also consider fashion, aesthetic, fit, fabric and design in conjunction with functionality of the lactating apparels. They should provide diverse sizes assortment for the lactating mothers.

\section{Keywords}

Functional, Apparels, Lactation, Lactating Mothers

\section{INTRODUCTION}

Apparels are articles of dress that are worn to cover, protect or decorate human body. [1] noted that apparel is an important facet of human constructed environment, surrounding an individual and that has bearing on the quality of life. [2] stated that apparel is a portable environment. Based on these assertions, apparels are complex but very important aspect of everyone's life. [3] defined apparels as garments or dresses that people put on. These include gowns, skirts, blouses, shirts, trousers and so on. Similarly, [4] argued that apparels are articles or materials put on the human body.

Functional apparel is a specially designed clothing item. [5] defined functional apparel is a relatively new and exciting segment of the technical textiles group. Functional apparel is known to perform multiple functions from aesthetic to basic protection from life threat and environmental hazards among others. Functional apparels can therefore be defined as a generic term that include all types of apparels or assemblies that are specifically engineered to deliver a pre-defined performance or functionality to the user over and above its normal functions [5].

Functional apparel assemblies are ergonomically designed to have a minimum inhibitory effect on movement and provide maximum comfort and performance to the user. Functional clothing is based on broad design parameters used in the development of products for a particular function and they are in six classes which include protective-functional, medicalfunctional, sports-functional, vanity-functional, crossfunctional assemblies and clothing for special needs group [6].

Functional apparel assemblies are ergonomically designed to have a minimum inhibitory effect on movement and provide maximum comfort and performance to the user. Special needs group means the group of people who deviate from the normal 
in physical, mental, social characteristics and activities to such an extent that they need special clothing [7]. Thus, special group in this case is considered as one whose clothing requirement is different from the normal group. This special group encompasses doctors, nurses, fire-fighters, soldiers, welders, astronauts, disabled, paraplegics, elderly, children, infant, pregnant and lactating women among others. Clothing for special needs may find an application in improving the quality of life for the above mentioned human population. This is because their body shape, size, mobility or dexterity and activities are significantly different from that of normal people. For the purpose of this study, lactating mothers serve as special needs group that needs functional lactating apparels. Functional lactating apparels are designed with special features that allow for easy lactation while enhancing discrete lactation. Lactating mothers are nursing or breastfeeding mothers. Lactating mothers are charged with the responsibility of breastfeeding the babies from birth to the first six months of life and continued breastfeeding up to two years of age or beyond.

Studies have focused on the development of functional apparel for cosmetologists, the relationship between the apparel needs of young lactating mothers and their sexual risk; adolescent soccer uniform needs and the specific garment types of the soccer uniform and many others. These studies pay little or no attention to the development of functional apparels for lactating mothers both within and outside Nigeria, particularly Taraba State of Nigeria. The needs and criteria for the development of functional apparels for lactating mothers have been largely ignored. Functional apparels that enhance modesty and easy lactation can contribute to saving lives of the babies by increasing mother's satisfaction and thereby willingness to lactate freely at anytime and anywhere. Based on the peculiar socio-cultural and religious configuration of the Taraba State in terms of its diversity, there is the need for a study that will provide insights on how functional apparels could be developed for lactating mothers. This is the gap in scholarship that this current study seeks to fill. Therefore, this study seeks to develop functional apparels to aid lactating mothers carry out their function of lactation discreetly to avoid exposure in Taraba State of Nigeria.

The study will be of great significance to the lactating mothers because the specially designed apparels will give the lactating mothers a whole new look that is practical, comfortable, convenient and attractive. Hence, the use of lactating apparels which are not only functional but also flattering to the figure will provide comfort and freedom in clothing and lactation. The lactating mothers will enjoy physical, emotional and psychological stability since lactation will become discreet and enjoyable. Therefore, this makes them appreciate apparels that do not just give them comfort and convenience but that which makes them look beautiful and feel good.

\section{LITERATURE REVIEW}

According to [8] Motherhood is a period in life that is characterized by so many activities which range from giving birth to a child, breast feeding the child and taking care of the child's overall needs. Below are some of the activities performed by lactating mothers that demand the needs for functional lactating apparel.

Lactation has been a critical public health intervention [9]. The World Health Organization [10] recommends exclusive breast-feeding for the first six months of life and continued breast feeding up to two years of age or beyond. Exclusive breast feeding is defined as, feeding infants only with breast milk, be it direct from the breast or expressed with no addition of any liquid or solid apart from drops or syrups consisting of vitamin, mineral supplements or medicine, and nothing else [11].

Lactation is of paramount importance and interest to diverse professionals in Pediatrics nursing endocrinology, Psychology, as well as Sociology and Anthropology [12]. Lactation is the medical term for yielding of milk by the mammary glands which leads to breast-feeding.

Functionality in apparel determines its usability performance. Apparel, by its nature has a restrictive effect on body movement as well as on transport of heat and moisture from the body. Apparel can be abrasive, noisy, smelly or unattractive. Apparel designed specifically for certain functionalities has been shown to cause heat stress, reduce task efficiency as well as rang-of-motion of the user. The process of designing and development therefore starts by first establishing the many requirements of the users, both as a guide for methodical design [13], scientific evaluations of design and in developing more specialized models of design process. It has also been used to advise businesses in effective product development practices through outreach programmes [14]

Functional apparel can be seen as a generic term used to include all types of apparels that are specifically engineered for special people. Functional apparels are relatively new and exciting segment of the technical textile group; one that is receptive to the new product development and abounding niche applications. Recently, there are breakthroughs and advances in technical fibres and fabrics in garment manufacturing technology; been fueled by the emergence of performance clothing. The field of functional apparel is wide and diverse with each function having its own specifications, material requirements, consequent technologies and processes [5]

According to [15], functional apparel provides special functionality to the wearer such as protection and assistance, which the conventional apparels cannot. However, this study will use the functional apparels to facilitate performance, body balance and reduce exposure of sensitive parts of a lactating mother. According to [5], standard classification used for technical textiles include protech (protective textiles), sportech (sports textiles), meditech (medical textile), and so on Design and development of functional apparel products is driven by the choice of materials as defined by social, psychological or physiological requirements of the user; choice of technologies as defined by desired functionality; and ergonomic, assembly methods, sizing and fitting among others.

The major aim of this investigation is to examine functional apparel needs of lactating mothers. Specific objectives of the study are to:

i. to access the various activities involved in lactation,

ii. design criteria adopted to produce functional apparels to accommodate the needs/activities of lactating mothers.

\section{METHODOLOGY 3.1 Area of the Study}

The area of the study is Taraba State of Nigeria. Taraba is one of the States located in North Eastern part of Nigeria. It is 
bounded in the North East by Bauchi and Gombe State, to the East by Adamawa State, then, to the North West by Plateau State. Both Nasarawa and Benue States further bound Taraba State in the West, while it shares international boundary with the Republic of Cameroon. Taraba State has three senatorial zones namely: North, South and Central senatorial zones. These zones have sixteen Local Government Areas with a total number of seventy four Maternal and Child Health $(\mathrm{MCH})$ facilities.

\subsection{Sample and Sampling Technique}

The sample size of this study was 288 respondents; drawn from the population of the study using a multi-stage sampling technique. The multi-stage sampling technique is a further development of cluster sampling. This was conducted by first selecting nine (9) LGAs through stratified sampling techniques. The second stage involved purposive sampling of towns within the selected LGAs that have MCH facilities and the third stage involved a disproportionate stratified random sampling of respondents from each selected town.

\subsection{Method of Data Analysis}

Both qualitative and quantitative methods of data analysis were employed in this study. Data collected from the interviews, sketches preferences and focus group discussions were adequately analyzed qualitatively.

\section{RESULTS AND DISCUSSIONS \\ 4.1 Various activities involved in lactation}

The data presented in Table 1 shows the mean rating and the standard deviation on various activities involved in lactation. Items one to fifteen showed the mean ratings of $3.88,3.59$, $3.79,3.90,3.84,3.56,3.77,3.84,3.92$, 3.89, 3.82, 3.95, 3.90, 3.96 , and 3.85 respectively with cluster mean rating of 3.83 and standard deviation of 6.21 which are more than 2.50 which is the cutoff point. Based on the mean cutoff point of 2.50 , it indicates that the 15 items represent the various activities involved in lactation. Inference drawn therefore is that lactating mothers in Taraba State engage in various activities during lactation.

Table 1: Mean ( $\overline{\mathbf{X}})$ and Standard Deviation (SD) on various activities involved in lactation

$$
\mathrm{N}=\mathbf{2 8 8}
$$

\begin{tabular}{|c|c|c|c|c|}
\hline $\mathbf{S} / \mathbf{N}$ & Lactating Activities & SD & DEC & $\overline{\mathrm{X}}$ \\
\hline 1. & Cleaning the nipple & 3.88 & 0.39 & SA \\
\hline 2. & Holding the baby in different positions to lactate & 3.59 & 0.79 & SA \\
\hline 3. & Calming the baby to settle before breast feeding & 3.79 & 0.53 & SA \\
\hline 4. & Supporting the breast for the baby to suck & 3.90 & 0.31 & SA \\
\hline 5. & Breastfeeding the baby & 3.84 & 0.42 & SA \\
\hline \multicolumn{5}{|c|}{ Caressing the baby to be awake to continue sucking } \\
\hline & if he or she is trying to sleep-off & 3.56 & 0.69 & SA \\
\hline 7. & Expressing breast milk for the baby & 3.77 & 0.46 & SA \\
\hline 8. & Cuddling the baby after lactation to keep warm & 3.84 & 0.39 & SA \\
\hline 9. & Changing the baby's pampers if wet or dirty & 3.92 & 0.29 & SA \\
\hline & . Backing the baby to be able to do other house tasks & 3.89 & 0.38 & SA \\
\hline & 1. Settling the baby in the bed/pram & 3.82 & 0.43 & SA \\
\hline & 2. Playing with the baby to show love during lactating & 3.95 & 0.22 & SA \\
\hline & 3. Bathing the baby & 3.90 & 0.29 & SA \\
\hline & 4. Washing the baby's clothes & 3.96 & 0.19 & SA \\
\hline & 5. Winding/burping the baby to remove air after lactation & 3.85 & 0.43 & SA \\
\hline
\end{tabular}

Key: $\overline{\mathrm{X}}=$ Mean, $\mathrm{SD}=$ Standard Deviation, $\mathrm{SA}=$ Strongly agree $\mathrm{DEC}=$ decision.

\subsection{Functional apparel needs of lactating mothers in Taraba State of Nigeria}

The data presented in Table 3 shows the mean rating and the standard deviation on functional apparels' needs for lactating mothers in Taraba State of Nigeria. This data showed the following mean ratings of $3.89,3.89,3.81,3.79,3.78,3.84$, $3.75,3.79,3.89,3.86,3.86$ and 3.85 respectively for items 16 27 , with cluster mean rating of 3.83 and standard deviation of
4.76 which are more than 2.50. Based on the mean cut-off point of 2.50 , it indicates that all the 12 items represent the functional apparel needs of lactating mothers in Taraba State of Nigeria. Therefore, lactating mothers in Taraba State of Nigeria have the need for functional apparels' which are represented in table 3 .

Table 2: Mean $(\overline{\mathbf{x}})$ and Standard Deviation SD on the functional apparels' needs for lactating mothers in Taraba State of Nigeria?

$\mathbf{N}=\mathbf{2 8 8}$

\begin{tabular}{lllll}
\hline \multicolumn{2}{l}{ ITEMS } & SD & DEC & $\overline{\mathbf{X}}$ \\
\hline 1. Apparels with Special openings with fastenings & 3.89 & 0.31 & SA \\
2. Apparels with proper means of coverage to enhance modesty & 3.89 & 0.31 & SA \\
3. Apparels that fit well to aid lactation & 3.81 & 0.42 & SA \\
4. Apparels that are fashionably made to meet mother's need for fashion & 3.79 & 0.42 & SA \\
5. Apparels that are aesthetically made to win mother's acceptance & 3.78 & 0.46 & SA \\
6. Apparels with functional features that are convenient to use & 3.84 & 0.37 & SA
\end{tabular}


7. Apparels that are comfortable to the skin

8. Apparel designs that are flexible to manipulate with ease to avoid struggling during lactation

9. Apparel designs that can offer support to the heavy weight of the breast $\&$ body during lactation

10. Functional apparel with absorbing capacity to suck up leaking breast milk

11. Functional apparel with good workmanship and quality material to withstand frequent use and washing

12. Functional apparels made of stretchy materials to accommodate body and breast size changes

$\begin{array}{lll}3.75 & 0.52 & \text { SA } \\ 3.79 & 0.46 & \text { SA } \\ 3.89 & 0.30 & \text { SA } \\ 3.86 & 0.47 & \text { SA } \\ 3.86 & 0.34 & \text { SA } \\ 3.85 & 0.38 & \text { SA }\end{array}$

Key: $\overline{\mathrm{x}}$ mean, $\mathrm{SD}=$ Standard deviation, $\mathrm{SA}=$ Strongly Agree, $\mathrm{DEC}=$ Decision .

\subsection{Design criteria adopted to produce functional apparels to accommodate the needs/activities of lactating mothers in Taraba State, Nigeria}

The data presented in Table 3 shows the mean rating and the standard deviation on functional apparels' needs for lactating mothers in Taraba State of Nigeria. This data showed the following mean ratings of $3.90,3.77,3.85,3.77,3.86,3.88$, $3.85,3.87,3.85,3.85,3.85,3.89,3.82,3.88,3.81,3.84,3.85$,
3.84 , and 3.81 respectively, cluster mean rating of 3.84 and standard deviation of 7.8 which are more than 2.50 . Based on the mean cut-off point of 2.50 , it indicates that all the 19 items represent the design criteria to be adopted to produce functional apparels to accommodate the needs/activities performed by lactating mothers in Taraba State, Nigeria. Therefore, there are needs for design criteria to be adopted to produce functional apparels to accommodate the needs/activities performed by lactating mothers in Taraba State, Nigeria.

Table 3: Mean $(\overline{\mathbf{x}})$ and Standard Deviation (SD) on design criteria to be adopted to produce functional apparels to accommodate the needs/activities performed by lactating mothers in Taraba State, Nigeria

$$
\mathbf{N}=\mathbf{2 8 8}
$$

\begin{tabular}{llll}
\hline ITEMS & SD & DEC & $\overline{\mathbf{X}}$ \\
\hline 22. Have easy lactating opening and fastenings & & & \\
23. Not exposing parts of mothers body & 3.90 & 0.29 & SA \\
24. Keep the baby cozy & 3.77 & 0.58 & SA \\
25. Not consecrating to baby & 3.85 & 0.43 & SA \\
26. Enhance modesty & 3.77 & 0.53 & SA \\
27. Supportive designs to carry the weight of the breast and body & 3.86 & 0.39 & SA \\
28. Be aesthetically pleasing & 3.88 & 0.35 & SA \\
29. Be flexible to accommodate body changes and breast & 3.85 & 0.37 & SA \\
fluctuation during lactation & & & \\
30. Enhance confidence & 3.87 & 0.35 & SA \\
31. Be functional & 3.85 & 0.39 & SA \\
32. Be fashionable & 3.85 & 0.44 & SA \\
33. Be comfortable & 3.85 & 0.41 & SA \\
34. Protect against breast milk leakages & 3.89 & 0.30 & SA \\
35. Be easy to clean & 3.82 & 0.42 & SA \\
36. Fit a range of sizes and figures & 3.88 & 0.35 & SA \\
37. Have good fit & 3.81 & 0.41 & SA \\
38. Be convenient to use & 3.84 & 0.47 & SA \\
39. Be of stretchy material & 3.85 & 0.36 & SA \\
40. Be of durable and qualitative work & 3.84 & 0.44 & SA \\
\hline
\end{tabular}

Key: $\overline{\mathbf{X}}=$ mean, $\mathrm{SD}=$ Standard deviation, $\mathrm{SA}=$ Strongly Agree, $\mathrm{DEC}=$ Decision

\subsection{Design criteria adopted to produce functional apparels to accommodate the needs of lactating mothers \\ The data presented in Table 4 shows the mean rating and the} standard deviation on functional apparels' needs for lactating mothers in Taraba State of Nigeria. This data showed the following mean ratings of $3.90,3.77,3.85,3.77,3.86,3.88$, $3.85,3.87,3.85,3.85,3.85,3.89,3.82$, 3.88, 3.81, 3.84, 3.85, 3.84 , and 3.81 respectively, cluster mean rating of 3.84 and standard deviation of 7.8 which are more than 2.50. Based on the mean cut-off point of 2.50 , it indicates that all the 19 items represent the design criteria to be adopted to produce functional apparels to accommodate the needs/activities performed by lactating mothers in Taraba State, Nigeria. Therefore, there are needs for design criteria to be adopted to produce functional apparels to accommodate the needs/activities performed by lactating mothers in Taraba State, Nigeria. 
Table 4: Mean $(\overline{\mathbf{X}})$ and Standard Deviation (SD) on design criteria to be adopted to produce functional apparels to accommodate the needs/activities performed by lactating mothers in Taraba State, Nigeria

\begin{tabular}{lccc}
\hline ITEMS & SD & DEC & $\overline{\mathbf{X}}$ \\
\hline 22. Have easy lactating opening and fastenings & 3.90 & 0.29 & $\mathrm{SA}$ \\
23. Not exposing parts of mothers body & 3.77 & 0.58 & $\mathrm{SA}$ \\
24. Keep the baby cozy & 3.85 & 0.43 & $\mathrm{SA}$ \\
25. Not consecrating to baby & 3.77 & 0.53 & $\mathrm{SA}$ \\
26. Enhance modesty & 3.86 & 0.39 & $\mathrm{SA}$ \\
27. Supportive designs to carry the weight of the breast and body & 3.88 & 0.35 & $\mathrm{SA}$ \\
28. Be aesthetically pleasing & 3.85 & 0.37 & $\mathrm{SA}$ \\
29. Be flexible to accommodate body changes and breast & & & \\
fluctuation during lactation & 3.87 & 0.35 & $\mathrm{SA}$ \\
30. Enhance confidence & 3.85 & 0.39 & $\mathrm{SA}$ \\
31. Be functional & 3.85 & 0.44 & $\mathrm{SA}$ \\
32. Be fashionable & 3.85 & 0.41 & $\mathrm{SA}$ \\
33. Be comfortable & 3.89 & 0.30 & $\mathrm{SA}$ \\
34. Protect against breast milk leakages & 3.82 & 0.42 & $\mathrm{SA}$ \\
35. Be easy to clean & 3.88 & 0.35 & $\mathrm{SA}$ \\
36. Fit a range of sizes and figures & 3.81 & 0.41 & SA \\
37. Have good fit & 3.84 & 0.47 & SA \\
38. Be convenient to use & 3.85 & 0.36 & SA \\
39. Be of stretchy material & 3.84 & 0.44 & SA \\
40. Be of durable and qualitative work & 3.81 & 0.52 & SA \\
\hline
\end{tabular}

Key: $\quad \overline{\mathbf{X}}=$ mean, $\mathrm{SD}=$ Standard deviation, $\mathrm{SA}=$ Strongly Agree, $\mathrm{DEC}=$ Decision

\subsection{Functional Apparels' Needs for Lactating Mothers in Taraba State of Nigeria}

A total of 12 functional apparels' needs for lactating mothers in Taraba State of Nigeria were determined. These include: Apparels with special openings with fastenings; Apparels with proper means of coverage to enhance modesty; Apparels that fit well to aid lactation; Apparels that are fashionably made to meet mother's need for fashion; Apparels that are aesthetically made to win other's acceptance; Apparels with functional features that are convenient to use; Apparels that are comfortable to the skin; Apparel designs that are flexible to manipulate with ease to avoid struggling during lactation; Apparel designs that can offer support to the heavy weight of the breast \& body during lactation; Functional apparel with absorbing capacity to suck up leaking breast milk. Functional apparel with good workmanship and quality material to withstand frequent use and washing; Functional apparels made of stretchy materials to accommodate body and breast size changes.

\subsection{Design criteria to be adopted to produce functional apparels to accommodate the needs/activities of lactating mothers in Taraba State, Nigeria}

A total of 19 design criteria to be adopted to produce functional apparels to accommodate the needs/activities performed by lactating mothers in Taraba State, Nigeria were established and organized under the following headings: Have easy lactating opening and fastenings; Not exposing parts of mothers body; Keep the baby cozy; Not consecrating to baby; Enhance modesty; Supportive designs to carry the weight of the breast and body; Be aesthetically pleasing; Be flexible to accommodate body changes and breast fluctuation during lactation; Enhance confidence; Be functional; Be fashionable; Be comfortable; Protect against breast milk leakages; Be easy to clean; Fit a range of sizes and figures; Have good fit; Be convenient to use; $\mathrm{Be}$ of stretchy material; $\mathrm{Be}$ of durable and qualitative work.

\section{SUMMARY, CONCLUSSION AND RECCOMENDATIONS}

The findings of this study were summarized based on the data obtained from the research questions and hypotheses disclosed that lactating mothers engage in various activities and are in need of functional apparels. Also, the study revealed that there are design criteria to be adopted in developing functional apparels in order to accommodate the needs/activities performed by lactating mothers in Taraba State, Nigeria. Notwithstanding, results also indicated that there are functional/aesthetic design features preferred by the lactating mothers in the study area. Furthermore, lactating mothers are continuously burdened with the problem of what clothing to wear. Many of them purchase large amounts of cloths both imported and locally made which do not enhance modesty and easy lactation. As a result, some mothers resort in discontinued lactation earlier than it supposed to be. Still, mothers that manage to use those clothing items ended up exposing essential parts of their body while breastfeeding in public. This attitude may create societal problems hence the need for development of functional apparels for lactating mothers in Taraba state becomes more imperative. Earlier on, some of the lactating mothers seems to be carried away by fashion and would not want to compromise their fashion lifestyle; this trend seems to lead the mothers to abandonment of the culturally accepted clothing code of the state.

This calls for the development of functional apparels for lactating mothers in Taraba State in order to proffer solutions to the stated problems. Lactating mothers engage in various 
identified operations/activities such also call for the design criteria to be adopted to produce functional apparels to accommodate these activities performed. Functional/aesthetic design features preferences, functional openings with fastening preferences as well as average body measurements of small, medium, and large sizes for bust, waist and hip. Both the judges and user models certified the developed functional apparels in terms of movement/mobility, fit, safety and protection, comfort, aesthetic, discreet and general utility.

Based on the findings made and the conclusion drawn, the following recommendations were made:

i. Seminars and workshops should be organized by appropriate authorities on ways of ameliorating the challenges militating against proper and decent dressing during lactation among the lactating mothers.

ii. The findings of this study should be communicated to the public through home economics professional bodies such as Home Economics Research Association of Nigeria (HERAN), Home Economics Council of Nigeria (HECON), International Federation of Home Economics (IFHE), and Home Economics Teachers Association of Nigeria (HETAN) through conferences, workshops and seminars.

iii. Manufacturers/designers/entrepreneurial and other clothing construction bodies should recognize functional apparel needs for lactating mothers during their process of construction.

iv. Manufacturers/designers/entrepreneurial and other clothing construction bodies should also consider fashion, aesthetic, fit, fabric design in conjunction with functionality of the lactating apparels.

v. Clothing manufacturers should provide apparels of diverse sizes assortment for the lactating mothers.

vi. Government, NGOs, policy makers etc should organize seminars, symposiums, and talks on the need for lactating mothers to accept the use of developed functional apparels to aids both exclusive breastfeeding and modesty.

vii. The present study is limited to only Taraba State; there is the need for more research to be carried out in other parts of the country.

\section{ACKNOWLEDGEMENTS}

Thanks to God Almighty for given me the strength, grace and ability to complete this research work. Appreciation goes to Prof. C.A. Igbo and my entire family for their support which lead to my academic success.

\section{REFERENCES}

[1] Carroll, M.D, (2001). Prevalence of obesity and trends in body mass index among us children and adolescents, 1989-2001. JAMA. 2002;307(5):483-90.
[2] Watkins, S. M. (2005). Clothing: The portable environment. Ame. IA: Iowa State University Press.

[3] Anyakoha, E.U. (2015). Home management for schools and colleges. Onitsha: Africana First Publishers Limited.

[4] Kaiser, S. B. (1997). The social psychology of clothing. Symbolic appearance in context $\left(2^{\text {nd }}\right.$ ed.). New York: Capital Cities Media

[5] Deepti, W.R. (2011). Attitudes toward clothing and selfconcept of physically handicapped and able-bodied university men and women. Home Economics Research Journal, 77, 234-240.

[6] Lawrence, R. A and Lawrence R. M (2011) Breastfeeding: A guide for the medical profession $\left(7^{\text {th }}\right.$ edition). Maryland HES, Missouri: Elsevier Mosby.

[7] Goldsworthy, M. (1981). Clothing for disabled people. B.P., Batesford Ltd; London, pp. 7-19.

[8] Neville, M. C. (2001). Anatomy and physiology of lactation: pediatric clinics of North America: 48(1), 13 35 .

[9] Bomer-Norton, C. (2013). Breastfeeding: A holistic concepts, Analysis. Public Health Nursing Journal.130 (5), 389-392

[10] World Health Organisation. (2003). Global Strategy for Infant and Young Child Feeding. Geneva: World Health Organisation.

[11] Plessis, D. (2009). Breastfeeding: mothers and health practitioners, in the context of private medical care in Gauteng. J Interdisipl Health Sci., 2(9), 1-4

[12] Uwakwe, C. B. U. (1996) The Psychosocial determinants of breastfeeding behaviour and practices among nursing mothers in rural and urban Nigeria Nig. J. Clin. Counselling Psycho, 2, 68 - 80 .

[13] Huck, J. Maganda, M., \& Kim, Y. (1997). Coverall for grass fire fighting. International Journal of Clothing Science and Technology, 9, 346-359.

[14] Loker, S. (2006). Cutting Edge Apparel business Guide. Ithaca, NY: Cornell University http://instract.cit.cornell. Edu/corses/cuttingedge/index2.html. Retrieved on $20^{\text {th }}$ July, 2016.

[15] Suh, F.G. (2010). Clothing and physical impairment: Joint effects on person perception. Home Economics Research Harrison, A. \& Thompson, K. (2001). Speed training: compression clothing. Clothing and Textiles Research Journal, 27, 31-44, 